W. A. Shear and J. K. Krejca-Cave millipeds of the United States. IX. A new species of the genus Taiyutyla (Diplopoda, Chordeumatida, Conotylidae) from caves in Sequoia and Yosemite National Parks, California, USA. Journal of Cave and Karst Studies, v. 73 , no. 2 , p. $93-98$. DOI: $10.4311 /$ jcks20101sc157

\title{
CAVE MILLIPEDS OF THE UNITED STATES. IX. A NEW SPECIES OF THE GENUS TAIYUTYLA (DIPLOPODA, CHORDEUMATIDA, CONOTYLIDAE) FROM CAVES IN SEQUOIA AND YOSEMITE NATIONAL PARKS, CALIFORNIA, USA
}

\author{
William A. Shear ${ }^{1}$ And Jean K. KreJCA ${ }^{2}$
}

\begin{abstract}
During surveys of cave life in Sequoia and Kings Canyon National Parks and Yosemite National Park, Taiyutyla loftinae, a new species of conotylid milliped, was collected and is described below. The new species occurs in eleven marble caves distributed throughout Sequoia National Park (Tulare County, California), two granite talus caves, and a single surface locality in Yosemite National Park (Mariposa County, California) and is best considered troglophilic, not troglobitic.
\end{abstract}

\section{INTRODUCTION}

Species of the milliped genus Taiyutyla Chamberlin 1952 are a dominant feature of the diplopod fauna of the Pacific Coast states of the United States and the Canadian province of British Columbia, from the Sierra Nevada of central California to Vancouver Island (Shear, 1971, 1976, 2004); a possible undescribed species, so far known only from female specimens, may extend the range of the genus north to Alaska and the Yukon (Shelley et al, 2009). Farther inland, species are also known from Montana and Idaho (Shear, 2004). While some species of the genus have been collected from caves and are known only from those habitats, none show troglomorphy, and they are best characterized as troglophiles.

Sixteen species have been named, and at least that number of additional species are awaiting description. Given the relatively limited distributions of most of them, even more may be expected in the future. Shear (2004) briefly discussed the difficulties in delimiting the genera Conotyla, Plumatyla, and Taiyutyla in the context of describing Taiyutyla lupus Shear 2004 from Vancouver Island. That species has gonopod characters that combine those of both Taiyutyla and Conotyla, the former genus limited to North America west of the Continental Divide and the latter to North America east of the Mississippi River. Taiyutyla loftinae n. sp., described below, is similar to T. lupus in this respect, and even shares the unusual somatic feature (for Taiyutyla) of prominent, recurved paranota on the metazonites. It may be that a new generic name will be required for these species in the future, when the additional undescribed species of Taiyutyla have been thoroughly studied.

Meanwhile, this species is described below because it is important for conservation purposes to provide a name for it. All specimens are deposited in the California Academy of Sciences collections, San Francisco, California.

\section{TAXONOMY}

Family Conotylidae Cook 1896

Genus Taiyutyla Chamberlin 1952

Taiyutyla loftinae, n. sp.

Figs. 1-13, Map 1

Suggested vernacular name: Loftin's Cave Milliped.

TYPES

Male holotype and male and female paratypes from Paradise Cave, Sequoia and Kings Canyon National Parks, Tulare Co., California, collected 30 April 2004 by J. Krejca et al. Additional material from other localities is listed below.

\section{ETYMOLOGY}

The new species is named for Vivian Loftin, who dedicates her time to cave science, conservation, and exploration and whose effervescent attitude has kept spirits high throughout numerous biological research expeditions.

\section{Diagnosis}

The two-branched anterior gonopods and their position relative to the posterior gonopod colpocoxites are unique among California Taiyutyla species.

\section{DESCRIPTION}

Male: length, $8.5 \mathrm{~mm}$, greatest width (measured across paranota), $1.75 \mathrm{~mm}$. Twenty-two to 24 ocelli in five rows in triangular eyepatch. Antennae long, slender. Pigmentation light brown to pale tan, faintly mottled darker purplish brown on head and anterior segments. Segments posterior to fifth with prominent, narrow paranota extending

\footnotetext{
${ }^{1}$ Department of Biology, Hampden-Sydney College, Hampden-Sydney VA 23943, USA wshear@hsc.edu (Corresponding Author)

${ }^{2}$ Zara Environmental LLC, 707 West FM 1626, Manchaca, TX 78652 USA jean@ zaraenvironmental.com
} 

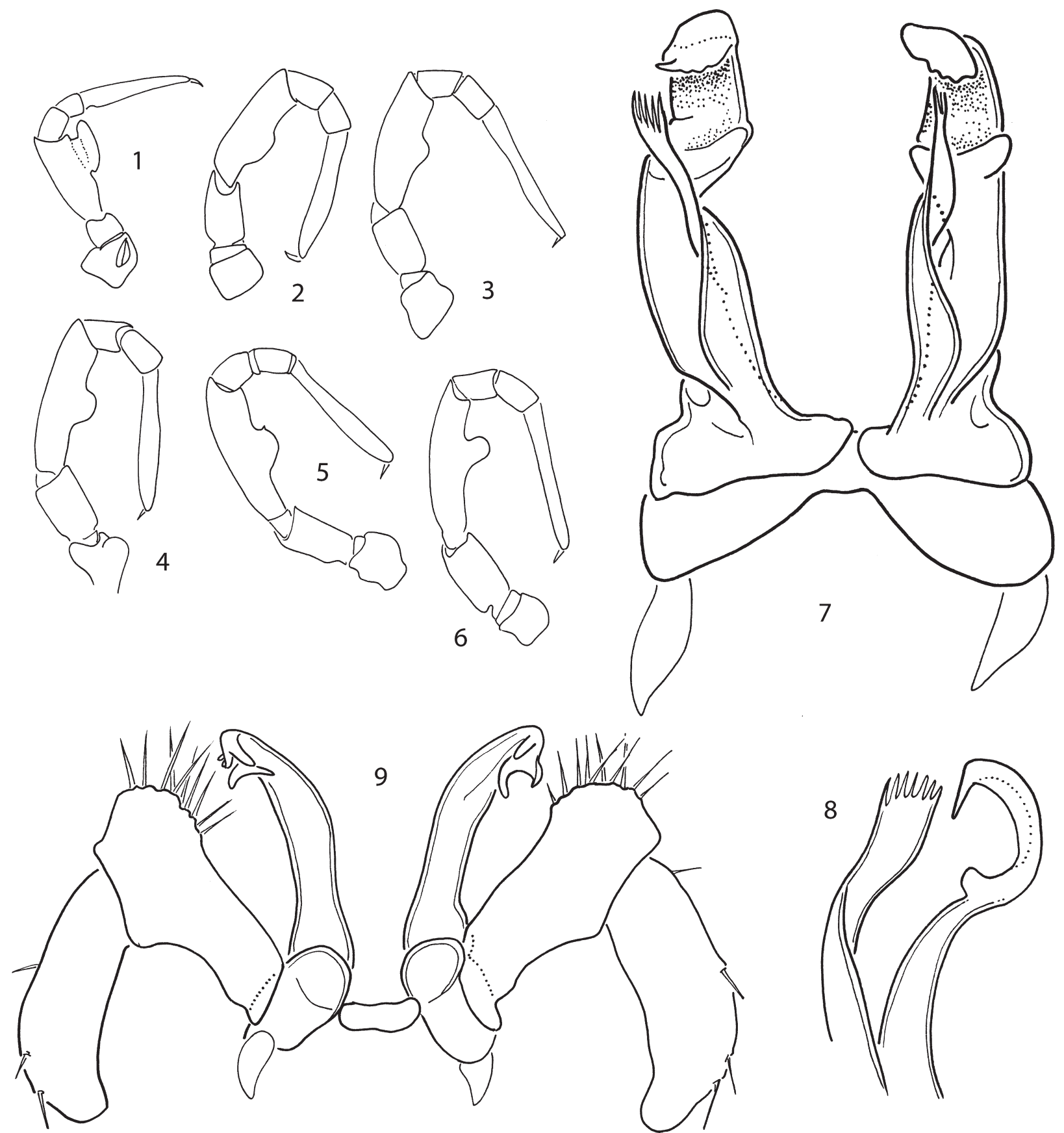

Figures. 1-9. Male Taiyutyla loftinae, n. sp. : Figs. 1-6: right pregonopodal legs, posterior views, drawn at $40 \times$. (1) leg 2; (2) leg 3; (3) leg 4; (4) leg 5; (5) leg 6; (6) leg 7. Figs. 7, 8: anterior gonopods, drawn at 100×. (7) anterior view; (8) lateral view of distal part of right gonopod. Fig. 9: posterior gonopods, posterior view, drawn at $100 \times$. Drawings not to scale.

approximately one-fourth metazonite width from lateral declevity of segment, slightly curved posteriorly, bearing two lateralmost segmental setae of each side (Fig. 12). Legpairs 2-7 with modified femora, pairs 4-7 larger than postgonopodal legs (Figs. 1-6). Femur two (Fig. 1) with large, distal, capitate knob bearing minute teeth; femora 37 with midlength median swelling, progressively larger on more posterior legs, forming distinct knob on seventh femur (Figs. 1-6). Anterior gonopods (Figs. 7, 8) with two branches, anterior flattened, lamellate, pectinate distally; posterior curved posteriorly, then sharply hooked anteriorly; in situ posterior branch passes laterally around posterior gonopod colpcoxites on each side. Posterior gonopods (Fig. 9) with distal and proximal telopodite articles subequal; colpocoxites simple, unbranched, with complex apices (Figs. 10, 11). Coxae of legpair 10 with prominent glands. Coxae of legpair 11 with long, mesobasal hooks projecting posteriorly. 

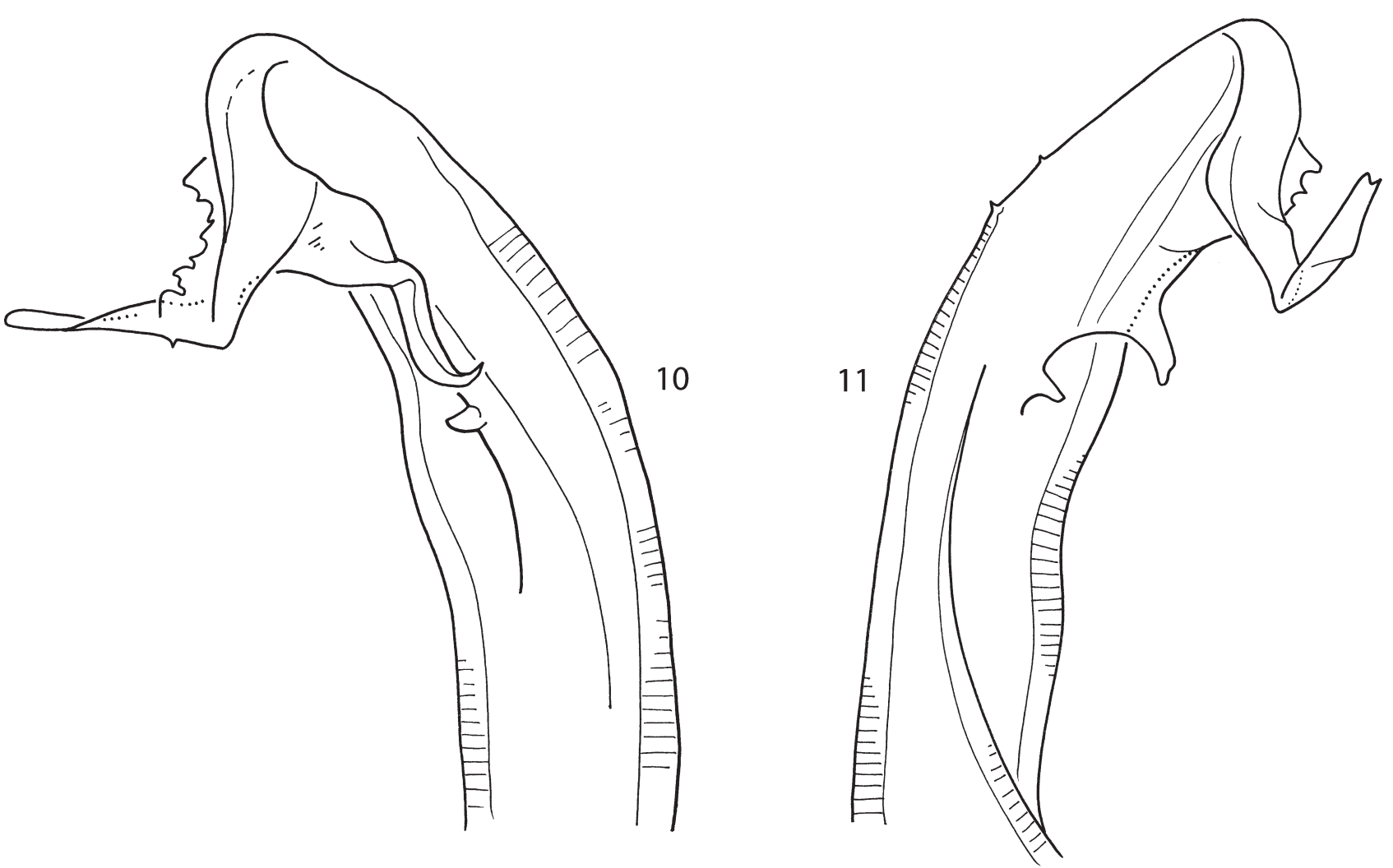

Figures. 10, 11. Male Taiytyla loftinae, n. sp., distal parts of posterior gonopod colpocoxites, posterior views, drawn at $400 \times$. (10) right; (11) left.

Female: length, $9.1 \mathrm{~mm}$, greatest width $1.8 \mathrm{~mm}$. Nonsexual characters as in male (Fig.12).

\section{Distribution}

Caves in Yosemite National Park and Sequoia and Kings Canyon National Parks, Mariposa and Tulare counties, California; see records listed below and Map 1. We do not provide geographical coordinates for the localities here, in the interests of conservation. The habitats in which $T$. loftinae occurs are delicate and sensitive to disturbance; the caves involved might be located only with some difficulty by those not familiar with them, and we believe we should not make that task any easier. The caves of Sequoia and Kings Canyon National Parks (Tulare County) occur in isolated marble bands separated by nonkarstic granite, and as such they appear on maps in discrete
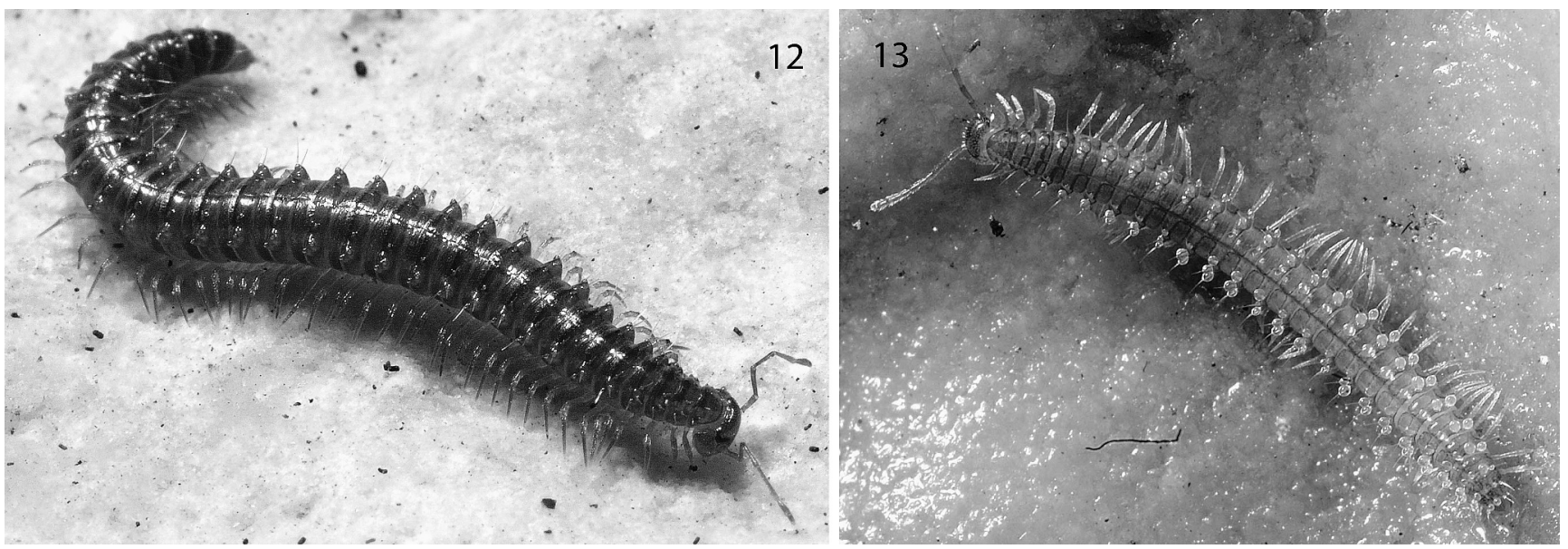

Figures. 12, 13. Live specimens of Taiyutyla loftinae in habitat. (12) female in $18^{\text {th }}$ Hole Cave; (13) juvenile in Paradise Cave, showing presumed defensive droplets on the segmental setae. 
Cave millipeds of the United States. IX. A new species of the genus Taiyutyla (Diplopoda, Chordeumatida, Conotylidae) from caves in Sequoia and Yosemite National Parks, California, USA

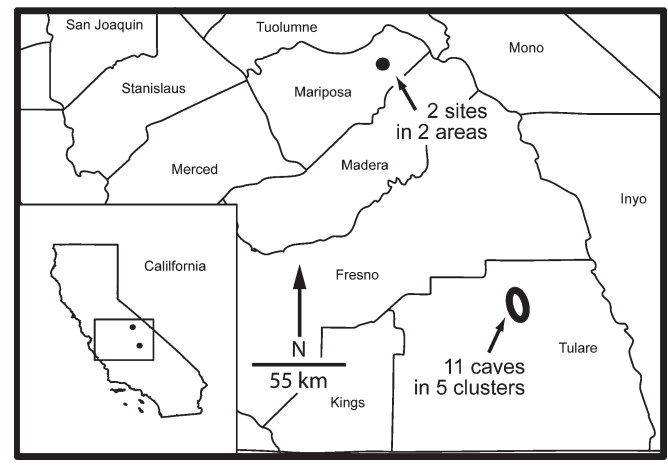

Map 1. Central California, showing distribution of Taiyutyla loftinae in two widely seperated areas.

clusters (see map in Shear and Krejca 2007). Five of these clusters were sampled during a multi-year inventory of cave fauna in the park, and we record T. loftinae from eleven caves, distributed through all five clusters. However, only juvenile specimens are known from Jordan Cave, the single Cluster 4 cave in which Taiyutyla specimens were taken (but note that they were observed but not collected in Bulah Cave, also in Cluster 4, though not mapped). Because of the strong similarities of these specimens to adult $T$. loftinae, we believe them to be the same species and so record them. Similarly, male specimens have not been collected in Lange Cave or Pet Cemetery Cave, both in Cluster 3, but $T$. loftinae was found in the other five caves in this cluster in which Taiyutyla was collected, so we have no reason to think these caves do not also support $T$. loftinae, especially given the near-identity of females from Lange Cave with females associated with $T$. loftinae males.

Nearly $200 \mathrm{~km}$ separate the two presently known areas of distribution for $T$. loftinae, a rather remarkable range for a Taiyutyla species, suggesting that it may be widespread in suitable habitats in the central Sierra Nevada.

Records: CALIFORNIA: MARIPOSA CO., Yosemite National Park, Spider Cave, 3 and 6 March 2009, Krejca, McDermid, Stock, Sas, male, female, juveniles; Indian Cave, 3 and 4 March 2009, Krejca, McDermid, Stock, Sas, male, juveniles; talus slope above Spider Cave, 2 March 2009, Sas, McDermid, female. TULARE CO., Sequoia and Kings Canyon National Parks, $8^{\text {th }}$ Hole Cave, 12 May 2004, Krejca, Sprouse, Snow, Fryer, 2 males, 2 females; 12 August 2003, Krejca, Despain, Olberg, 2 females, 15 juveniles; Bear Den Cave, 18 July 2003, Krejca, Loftin, Fryer, Walck, juvenile, 1 May 2004, Krejca, Snow, Sprouse, 2 males, 2 females, 5 juveniles; Bulah Cave, August 2002, Krejca, Fryer, Olmbeck (sight record); Crystal Cave, 17 July 2003, Krejca, Loftin, juvenile, 10 August 2003, Krejca, Taylor, male; Hurricane Crawl Cave, 16 July 2003, Krejca, Loftin, Snow, Fryer, male, 9 juveniles; Jordan Cave, 12 July 2004, Krejca, Gluesenkamp, Fryer, female; Lange Cave, 6 May 2004, Krejca,
Sprouse, Fryer, Walck, 5 females, 2 juveniles; Wilburn Cave, 15 May 2004, Krejca, Snow, Fryer, Boiano, male; Palmer's Cave, 27 July 2003, Krejca, Loftin, male; Pet Cemetary Cave, 11 May 2004, Krejca, Loftin, Fryer, Walck, female, 3 juveniles; Weiss Raum Cave, 10 May 2004, Olmbeck, 2 males, 2 females, juvenile.

\section{HABITAT}

All of the Tulare County localities are caves formed by gradual dissolution of marble by water. The caves with this species in Mariposa County are granite talus caves formed instantaneously as a result of a rock avalanche (Wieczorek et al. 1999). The habitat in these granite talus caves is very similar to that in caves formed in sedimentary rock by dissolution, with true darkness, humidity at or near saturation, and limited nutrient input. These granite talus caves have a variety of passageways, narrow squeezes and large rooms, and are not extensive $(<100 \mathrm{~m}$ long, $<20 \mathrm{~m}$ deep). A handful of marble caves also exist in Yosemite National Park in the Forsyth Mountain area (Tuolumne County), and inventories of four of these caves did not yield T. loftinae. Possibly the elevation is too high (2900 meters) or the detectability is low enough that the brief visits there did not turn up any specimens. For maps and descriptions of Sequoia and Kings Canyon National Parks caves, see Despain (2003).

In addition to cave localities, we collected one individual from underneath rocks on a granite talus slope near Spider Cave. This surface locality is somewhat contiguous with the caves there, considering that the talus slopes are laterally extensive and deep. This finding supports our ecological designation of this species as a troglophile.

Elevations where this species were recorded range from 1100 meters to 2900 meters. Extensive sampling effort (25\% of the significant caves visited, and greater than $25 \%$ of the cave visits) occurred at lower-elevation sites, between 500 and 1000 meters, but the species was not found there. Some sampling effort also occurred above 3000 meters, with no records of T. loftinae. Based on the results of this sampling effort, we propose that the range of the species may be limited to higher elevations, but not above $3000 \mathrm{~m}$. However, it is not limited to a certain type of karst geology.

\section{Microhabitat}

Temperature data are available for the microhabitat of 78 of the 85 collected individuals. The temperature average for those 78 individuals is $9.4{ }^{\circ} \mathrm{C}$ (range $=2.5^{\circ}$ to $12^{\circ}$, standard deviation $\left.=1.6^{\circ}\right)$. Humidity for 14 collections averaged $95 \%$ (range $=91.8$ to $100 \%$, standard deviation $3.3 \%$ ). In-cave location data are available for 53 individuals, with an average distance into the cave from the entrance of 56 meters (range $=3$ to 180 meters, standard deviation $=68$ ). Time spent searching by surveyors gives an idea of abundance, and is available for 82 individuals 
collected. The average time spent to find an individual was 69 person-minutes (range $=25$ to 261 person-minutes, standard deviation $=50$ ). Substrate data for 40 individuals showed the majority ( $83 \%$ ) were found approximately equally in the following environments: under rocks (on silt or other types of floors), on woody debris, or on rocks that were on a floor of woody debris. The remainder were found in other environments, such as calcite ceilings, bedrock walls, and silt floors.

\section{REMARKS}

The specimens of $T$. loftinae were collected in connection with a survey of the fauna of the caves of Sequoia and Kings Canyon National Parks and Yosemite National Park carried out under the direction of JKK. Other collections from this work have already been reported on; Shear and Krejca (2007) described two new species of the striariid milliped genus Amplaria (A. muiri Shear \& Krejca 2007 and $A$. adamsi Shear \& Krejca 2007), and Shear and Shelley (2008) described a new genus and species of macrosternodesmid, Sequoiadesmus krejcae Shear \& Shelley 2008, all from Sequoia and Kings Canyon National Parks. Shear et al. (2009), in a paper on new cave-dwelling polydesmidans from the southwestern states, named Pratherodesmus despaini Shear 2009, another macrosternodesmid from Sequoia, and yet another Sequoia Pratherodesmus species awaits the collection of further specimens for description. Of these species, it is likely that only Amplaria muiri, which shows reduced pigmentation and ocellus number when compared to other, surface-dwelling Amplaria, may be cave-limited. The other species so far described show no obvious adaptations to life underground, as exemplified by Taiyutyla loftinae, which has pigmentation and the standard number of ocelli for surface Taiyutyla in the same size range. The legs and antennae of $T$. loftinae are not inordinately elongate. We expect that collecting on the surface in the parks will reveal the presence of this species, but work has so far focused on the caves, making the exact ecological status of the millipedes found there difficult to clarify.

Taiyutyla loftinae is not a typical Taiyutyla species in the conformation of its gonopods. The two-branched anterior gonopods are found otherwise only in $T$. variata Shear 1976 (Josephine Co., Oregon) and T. lupus Shear 2004 (Vancouver Island, British Columbia), with the loftinae form closest to T. lupus. Having the posterior branch of the anterior gonopod pass lateral to the posterior gonopod colpocoxite is characteristic of the genus Conotyla, and among Taiyutyla species is found only in $T$. lupus and T. loftinae. The posterior gonopod colpocoxites, however, are much simpler than are generally found in Taiyutyla, lacking additional basal branches and an otherwise characteristic mid-distal, posterior fimbriate region or process. Like $T$. lupus, $T$. loftinae also has very prominent paranota (see Fig. 5, Shear, 2004). Further- more, T. loftinae is evidently unique among described Taiyutyla species, and indeed all known conotylids, in the modifications of male legpair 2, a strong, oblong prefemoral process (Fig. 1). All the pregonopodal legpairs except the first have modified prefemora.

Whether some division of the genus Taiyutyla will be justifiable in the future depends on the study of a substantial number of undescribed species currently in collections; it is also quite likely that additional species will turn up in numbers, if systematic collecting for them in California is ever undertaken.

As shown in Fig. 13, living animals often show droplets attached to the segmental setae. One explanation for this might be condensation in the saturated cave environment, but they do not appear on all specimens (Fig. 12, for example). Trichopetalid millipeds often show very similar droplets (Shear, 2003; 2010) that emerge from the sockets at the bases of the setae and work their way out to the tips. One of us (WS) has hypothesized that this is part of a defensive strategy, since in the trichopetalids the droplets are very sticky. If Taiyutyla loftinae is exhibiting the same behavior, this is the first report of it from a conotylid milliped.

\section{ACKNOWLEDGMENTS}

A National Park Service grant that funded the Sequoia collection trips was written by Danny Boiano and Joel Despain, who, along with fellow NPS personnel Annie Esperanza and Shane Fryer, assisted with every detail of caving trip logistics and participated extensively in the study. National Park Service and Yosemite Fund resources funded the collections in Yosemite National Park, where Greg Stock initiated and coordinated the efforts. Some of the specimens reported on here were originally transmitted to Rowland Shelley of the North Carolina State Museum of Natural History, who recognized them as conotylids and passed them along to WAS for further study. This paper is published under the auspices of a Preserving and Extending Expertise in Taxonomy (PEET)grant (DEB05-29715) to WAS, Jason Bond, and Petra Sierwald, and with the help of a grant from the Faculty Development Committee of Hampden-Sydney College. Despite the infirmities of age, Asa Kreevich continues to provide invaluable support.

\section{REFERENCES}

Chamberlin, R.V., 1952, Two Oregon millipeds of the order Chordeumid, Natural History Miscellanea (Chicago Academy of Sciences), no. 113, p. $1-3$.

Despain, J., 2003, Hidden Beneath the Mountains: Caves of Sequoia and Kings Canyon National Parks, Dayton, Ohio, Cave Books, 128 p.

Shear, W.A., 1971, The milliped family Conotylidae in North America, with a description of the new family Adritylidae (Diplopoda: Chordeumida): Bulletin of the Museum of Comparative Zoology, v. 141, p. $55-98$.

Shear, W.A., 1976, The milliped family Conotylidae (Diplopoda, Chordeumida): Revision of the genus Taiyutyla, with notes on recently proposed taxa: American Museum Novitates, no. 2600, 22 p. 
Cave millipeds of the United States. IX. A new species of the genus Taiyutyla (Diplopoda, Chordeumatida, Conotylidae) from caves in Sequoia and Yosemite National Parks, California, USA

Shear, W.A., 2003, The milliped family Trichopetalidae, Part 1: Introduction and genera Trigenotyla Causey, Nannopetalum, n. gen., and Causeyella n. gen. (Diplopoda: Choredumatida, Cleidogonoidea.: Zootaxa 321, p. 1-36.

Shear, W.A., 2004, Two new species in the milliped genus Taiyutyla from British Columbia, Canada, and Washington, USA (Diplopoda, Chordeumatida, Contylidae): Myriapodologica, v. 8, p. 13-20.

Shear, W.A., 2010, The milliped family Trichopetalidae, Part 2: The genera Trichopetalum, Zygonopus and Scoterpes (Diplopoda: Chordeumatida, Cleidogonoidea: Zootaxa 2385, p. 1-62.

Shear, W.A., and Krejca, J.K., 2007, Revalidation of the milliped genus Amplaria Chamberlin 1941 (Diplopod, Chordeumatida, Striariidae) and description of two new species from caves in Sequoia and Kings Canyon National Parks, California: Zootaxa, v. 1532, p. 23-39.

Shear, W.A., and Shelley, R.M., 2008, Cave millipeds of the United States. VI. Sequoiadesmus krejcae, n. gen., n. sp., from Sequoia and Kings
Canyon National Parks, California, USA (Diplopoda, Polydesmida, Polydesmidea, Macrosternodesmidae): Zootaxa, v. 1693, p. 41-48.

Shear, W.A., Taylor, S.J., Wynne, J.J., and Krejca, J.K., 2009, Cave millipeds of the United States. VIII. New genera and species of polydesmidan millipeds from caves in the southwestern United States (Diplopoda, Polydesmida, Macrosternodesmidae): Zootaxa, v. 2151, p. 47-65.

Shelley, R.M., Medrano, M.F., Shear, W.A., Ovaska, K., White, K.J., and Havard, E.I., 2009, Distribution extensions of the milliped families Conotylidae and Rhiscosomididae (Diplopoda: Chordeumatida) into northern coastal British Columbia and southern Alaska: Insecta Mundi, article no. 71, p. 1-6.

Wieczorek, G.F., Morrissey, M.M., Iovine, G., and Godt, J., 1999, Rockfall potential in the Yosemite Valley, California: U.S. Geological Survey Open-file Report 99-578, URL http://pubs.usgs.gov/of/1999/ ofr-99-0578/ [accessed 9 August 2009]. 